\title{
Posterosuperior Lesion has a High Risk of Lateral and Central Nodal Metastasis in Solitary Papillary Thyroid Cancer
}

\author{
Chandan Kumar Jha · Anjali Mishra
}

Published online: 11 February 2015

(C) Société Internationale de Chirurgie 2015

\section{Dear Sir,}

We read with interest the article entitled "Posterosuperior Lesion has a High Risk of Lateral and Central Nodal Metastasis in Solitary Papillary Thyroid Cancer" by Lee et al. [1]. This is an interesting study describing the relationship between location of solitary papillary thyroid cancer (PTC) and cervical lymph node metastases pattern. We have few comments and queries to make.

(1) What was the average size of the thyroid lobe? Did majority of the patients included in this study also have co-existent goiter? The dimensions of a normal thyroid gland range from $40-60 \mathrm{~mm}$ in length and $13-18 \mathrm{~mm}$ in transverse and antero-posterior (A-P) diameter [2, 3]. Considering the dimensions of a normal thyroid gland, it seems a bit difficult to divide it into nine portions and particularly in coronal plane (AP diameter about $2 \mathrm{~cm}$ ) unless most of the tumors are small $(<1 \mathrm{~cm})$ or thyroid is enlarged it is difficult to divide it into three parts anterior, middle, and posterior and locate tumor within one of these portions. Forty patients in this study had tumor measuring more than $2 \mathrm{~cm}$ in size but only 21 of them were in "W" category, i.e., occupying more than one portions of the 9 portions proposed by the authors.
Authors have mentioned that the 178 patients have tumor measuring less than $2 \mathrm{~cm}$, but they did not provide the mean tumor size, but it seems that most of the tumors were small. We believe that the findings of this study would be more pertinent for papillary microcarcinoma rather than the bigger tumor; and in that scenario, it would definitely be of great help.

(2) Authors have provided the percentage of metastases in various levels of cervical lymph nodes. Did they also find any correlation of location of the PTC within thyroid gland with a particular level of lymph node involvement?

\section{References:}

1. Lee DJ, Lee KH, Kim JH, Kwon KH, Yoon DY, Rho YS (2014) Posterosuperior lesion has a high risk of lateral and central nodal metastasis in solitary papillary thyroid cancer. World J Surg. doi:10.1007/s00268-014-2839-x

2. Khati N, Adamson T, Johnson KS, Hill MC (2003) Ultrasound of the thyroid and parathyroid glands. Ultrasound Q 19:162-176

3. Choi SH, Kim EK, Kim SJ, Kwak JY (2014) Thyroid ultrasonography: pitfalls and techniques. Korean J Radiol 2014(15):267-276. doi:10.3348/kjr.2014.15.2.267.Epub
C. K. Jha · A. Mishra ( $ه)$

Department of Endocrine Surgery, Sanjay Gandhi Postgraduate

Institute of Medical Sciences, Raebareli Road,

Lucknow 226 014, India

e-mail: anjali@sgpgi.ac.in; anjali_mishra2000@yahoo.com 